Gut, 1973, 14, 753-762

\title{
The effect of cholecystectomy on bile salt metabolism
}

\author{
E. W. POMARE AND K. W. HEATON \\ From the University Department of Medicine, Royal Infirmary, Bristol
}

SUMMARY Isotopic bile salt studies have been performed in 13 cholecystectomy patients and 10 matched controls using labelled taurocholate and deoxycholic acid. Cholecystectomy subjects have reduced pools of both primary bile salts, cholate and chenodeoxycholate, while the deoxycholate pool remains normal in size. As a result of these changes, the total bile salt pool is reduced to almost half its normal size and deoxycholate becomes the predominant bile salt. The half-life of taurocholate is reduced but, because its pool size is diminished, the daily synthesis of taurocholate remains normal. There is accelerated transfer of ${ }^{14} \mathrm{C}$ from taurocholate- $24-{ }^{14} \mathrm{C}$ to its metabolites in bile, especially deoxycholate conjugates. In four subjects studied pre- and postoperatively similar changes occurred in all the above parameters.

All these data can be explained by the fact that the bile salt pool circulates during fasting as well as during digestion. The consequences of this are (1) increased exposure of bile salts to intestinal bacteria and hence increased bacterial degradation; (2) continuous passage of the bile salt pool through the liver, and therefore continuous and presumably enhanced feedback inhibition of hepatic bile salt synthesis.

The reservoir function of the gallbladder influences the size, kinetics, metabolism, and composition of the bile salt pool. We suggest that no study of bile salt metabolism is complete without some assessment of gallbladder status.

Conjugated bile salts are secreted by the liver and stored in the gallbladder. When food is taken the gallbladder contracts and the bile salt pool enters the intestine. Most of this pool is reabsorbed but before this can happen some bile salts have been attacked and altered by bacteria in the ileum and colon (Hofmann, 1968; Dowling, 1972; Heaton, 1972).

In the absence of the gallbladder, feeding is not followed by the normal early peak in duodenal bile salt concentrations, but otherwise these concentrations are probably normal and dietary fat is incorporated normally into the micellar phase of intestinal content (Sjövall, 1959; Turnberg and Grahame, 1970; Simmons and Bouchier, 1972). Together with the normal faecal fat output of cholecystectomy patients (Krondl, Vavrinkova, and Michalec, 1964), these facts suggest that after the gallbladder is removed there is no significant deficiency of bile salts in the intestine. Beyond this, little is known of the role of the gallbladder in the bile salt economy or of the effects of cholecystectomy

Received for publication 7 June 1973. on the pool size and metabolism of bile salts. While studying hyperlipidaemic patients, Wollenweber, Kottke, and Owen (1967) and Kottke (1969) noticed that those patients who had undergone cholecystectomy had small, rapidly turned over pools of the two primary bile acids, cholic and chenodeoxycholic, but they did not measure the size of the total bile salt pool. Preliminary studies in dogs have suggested that the total bile salt pool is reduced after cholecystectomy (Wollenweber, Kottke, and Owen, 1966). In man, there are no previous reports of the size of the total bile salt pool after cholecystectomy. This information is of particular interest since it has recently been found that, after cholecystectomy, hepatic bile which was previously supersaturated with cholesterol becomes unsaturated (Simmons, Ross, and Bouchier, 1972; Shaffer, Braasch, and Small, 1972).

It can be assumed that, in the absence of the gallbladder, the bile salt pool is passing down the intestine and meeting intestinal bacteria constantly throughout the 24 hours, whereas in normal subjects this is so only during digestion. Since the fate of bile salts is determined within the intestine, it seems 
pertinent to ask two questions: (1) Does loss of the gallbladder reservoir cause increased bacterial alteration of bile salts? (2) Does it alter the turnover rate of bile salts? To answer these questions, and at the same time to determine the effect on bile salt pool size, we have performed isotopic bile salt studies in cholecystectomy subjects and in controls.

\section{Subjects and Methods}

The subjects studied were a control group of 10 healthy women aged 41-58 yr (mean $51 \mathrm{yr}$ ) and 13 women aged 46-63 yr (mean 56 yr) who had undergone cholecystectomy six months to seven years previously and were otherwise in good health. In 11 of the cholecystectomy patients, radiolucent gallstones had been shown at cholecystography. In the other two patients, the gallbladder was found at operation to be completely normal in one and to contain a small benign polyp in the other. In all the controls oral cholecystography showed normal concentration and contraction. All subjects were eating a normal, unrestricted diet.

The kinetics of labelled taurocholate were studied in all 10 controls and in 11 of the cholecystectomy subjects (nine with and two without gallstones). The methods used have previously been described in detail (Austad, Lack, and Tyor, 1967; Heaton, Austad, Lack, and Tyor, 1968). Studies were carried out over a period of five to six days. On day 1 , approximately $5 \mu \mathrm{Ci}$ of sodium taurocholate-24-14 $\mathrm{C}$ (Tracerlab GB Ltd, Weybridge or Radiochemical Centre, Amersham) of high specific activity and mean $98 \%$ radiochemical purity was injected intravenously at 9 a.m. Bile-rich duodenal fluid (2-6 ml depending on its concentration) was aspirated each morning for the next four to five days following an overnight fast and intubation of the duodenum. In the controls, bile flow was stimulated by the injection of cholecystokinin-pancreozymin (Karolinska Institute, Stockholm, or Boots, Nottingham). Bile samples were extracted with absolute alcohol and analysed by thin-layer chromatography (Hofmann, 1962). The rate of fall of taurocholate specific activity was determined by assaying the eluted bile salt spectrophotometrically and by measuring its radioactivity with liquid scintillation counting. From these data, the half-life, pool size, and daily synthesis of taurocholate were calculated. The slopes of the specific activity decay curves were calculated by linear regression analysis using a Hewlett-Packard desktop computer. The mean correlation coefficient ( \pm SD) of these lines, indicating the goodness of fit, was $0.992 \pm 0.009$ for the controls and $0.995 \pm$ 0.006 for the cholecystectomy subjects.

In five cholecystectomy subjects, kinetic studies were performed using deoxycholic acid-24- ${ }^{14} \mathrm{C}$ (International Chemical and Nuclear Corporation, Irvine, California) of high specific activity and greater than $99 \%$ radiochemical purity. The plan of these studies was identical to those using labelled taurocholate. Measurements of deoxycholate specific activity were made on the combined glycodeoxycholate and taurodeoxycholate fractions, the eluted bile salts being estimated chemically by the salicylaldehyde reaction (Bruusgaard, 1970) and for radioactivity by liquid scintillation counting.

The recirculation of labelled metabolites of taurocholate- $24-{ }^{14} \mathrm{C}$ was studied following TLC separation of the conjugated bile salt fractions (glycine-dihydroxy, glycocholate, taurine-dihydroxy, and taurocholate). These fractions were identified by exposure to iodine vapour, and the bands of silica gel containing them were scraped into counting vials and shaken with a $2: 1$ mixture of a toluenebased scintillation fluid and Triton-X-100. The

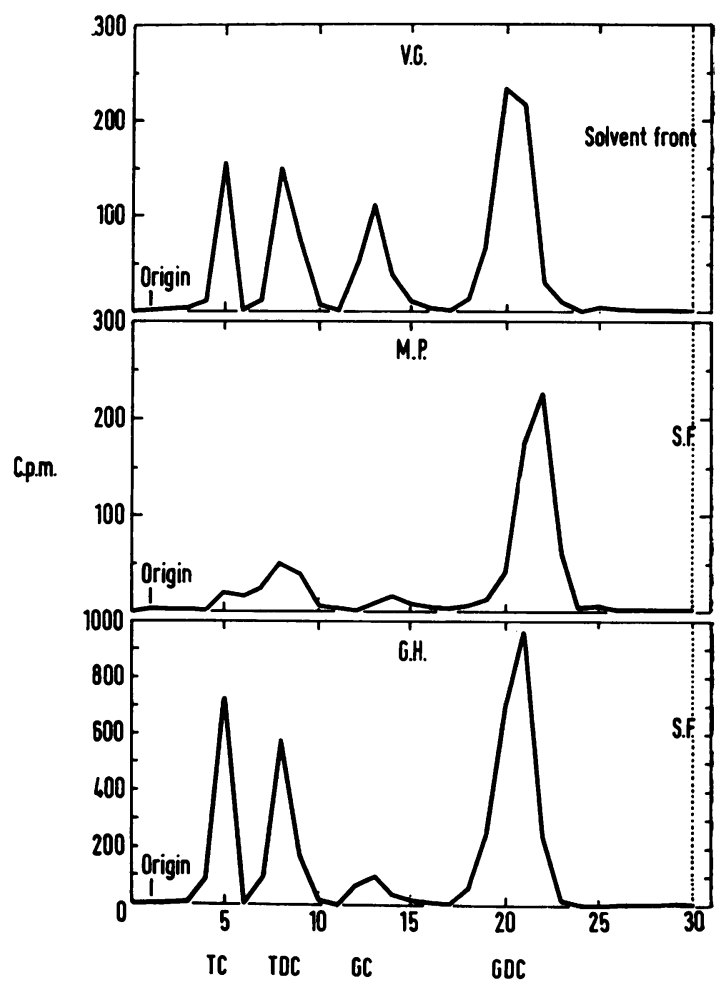

Fig 1 Zonal radioactive scans of silica-gel chromatograms of 96-hour bile samples from three cholecystectomy subjects (V.G., M.P., and G.H.). The positions of bile salt standards run in parallel are shown below (TC taurocholate, TDC taurodeoxycholate, GC glycocholate, $G D C$ glycodeoxycholate). Note the absence of any peaks other than the four identified fractions. 
particles were allowed to settle for 24 hours and radioactivity was measured by liquid scintillation counting. For each bile sample, the total number of counts in all three metabolites (glycodeoxycholate, glycocholate, and taurodeoxycholate) and also in the deoxycholate conjugates was expressed as a percentage of the total radioactivity in that sample. In three cholecystectomy subjects found to have a high proportion of biliary radioactivity in deoxycholate conjugates, the distribution of radioactivity in the 96-hour sample was checked by a strip counting method. Silica gel chromatograms were divided into $5 \mathrm{~mm}$ strips. Each strip was transferred to a vial containing a toluene-based scintillant and Triton-X-100 and its contained radioactivity was counted. By this means it was established that all the radioactivity in the chromatogram was confined to four well defined peaks corresponding in $R_{\boldsymbol{f}}$ to taurocholate, taurodeoxycholate, glycocholate, and glycodeoxycholate standards (fig 1). Any unusual metabolites such as 7-ketodeoxycholate would have been detected as extra peaks by this technique.

The relative proportions of the three main bile salts - cholate, chenodeoxycholate, and deoxycholate-were measured in each sample of bile by minor modifications of the method of Bruusgaard (1970) as described by Low-Beer, Heaton, Pomare, and Read (1973). The glycine to taurine conjugation ratio (G/T ratio) was calculated after measuring the total glycine and total taurine conjugates enzymatically.
The total bile salt pool and component pools were calculated from the measured taurocholate or deoxycholate pools and the ratios of the other bile salt fractions to them.

Statistical significance of differences was tested by Student's $t$ test and regression analysis.

\section{Results}

KINETICS OF TAUROCHOLATE-24-14 C

Figure 2 shows the half-life of radioactive taurocholate in the two groups studied and demonstrates that this bile salt is turned over more rapidly in the operated subjects. The mean values $( \pm$ SD) for the half-life were $1.65 \pm 0.61$ days in the control group and $0.97 \pm 0.30$ days in the cholecystectomy group $(P<0.005)$.

The pool size of taurocholate was significantly smaller in the cholecystectomy group (fig. 3), the mean values $( \pm \mathrm{SD})$ being $191 \pm 116 \mathrm{mg}$ compared with $358 \pm 177 \mathrm{mg}$ in the controls $(\mathrm{P}<0.01)$. There was no difference in the daily synthesis of taurocholate in the two groups, the mean values $( \pm \mathrm{SD}$ ) being $149 \pm 47 \mathrm{mg}$ in the controls and $142 \pm 63 \mathrm{mg}$ in the cholecystectomy subjects (fig 4).

KINETICS OF DEOXYCHOLIC ACID-24-14C In the five cholecystectomy subjects given radioactive deoxycholic acid the half-life of this bile acid averaged $2 \cdot 18$ days, the pool size $0.47 \mathrm{~g}$, and the daily synthesis $148 \mathrm{mg} /$ day (see table I).

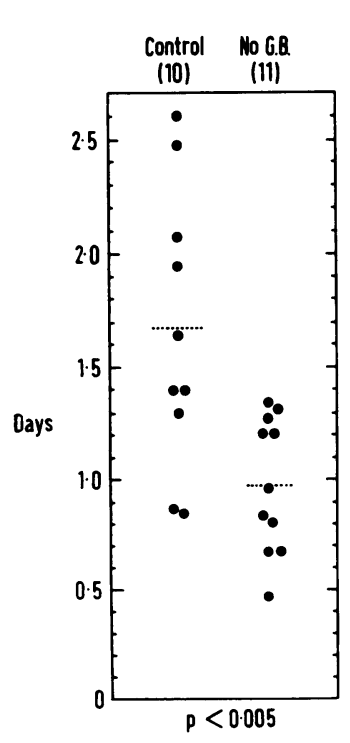

Fig 2

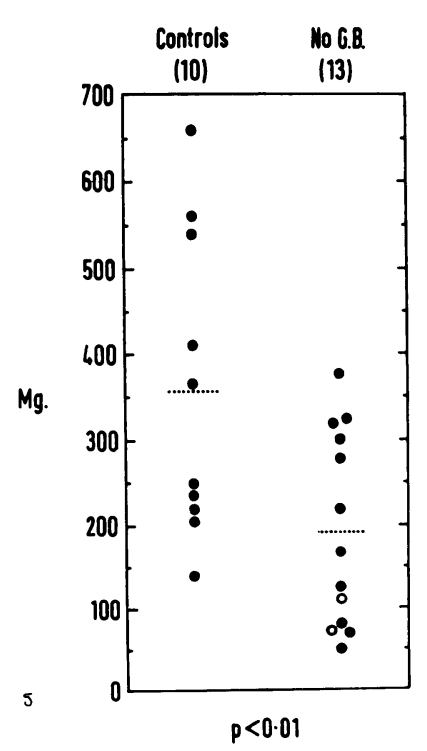

Fig 3
Fig 2 The half-life of taurocholate in days in the two groups studied. (G.B. = gallbladder)

Fig 3 The pool size of taurocholate in the two groups. The open circles represent values calculated from deoxycholic acid-24-14 C studies. 


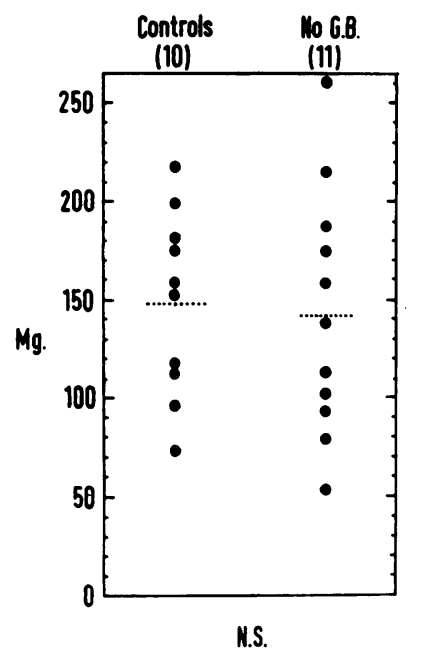

\begin{tabular}{lllll}
\hline Subject & $\begin{array}{l}\text { Age } \\
(\text { years })\end{array}$ & $\begin{array}{l}\text { Half-life } \\
(\text { days })\end{array}$ & $\begin{array}{l}\text { Pool Size } \\
(\mathrm{g})\end{array}$ & $\begin{array}{l}\text { Daily Turnover } \\
(\text { mg/day })\end{array}$ \\
\hline 1 & 55 & 2.20 & 0.42 & 132 \\
2 & 62 & 2.27 & 0.66 & 201 \\
3 & 58 & 1.80 & 0.52 & 200 \\
4 & 63 & 2.05 & 0.13 & 44 \\
5 & 54 & 2.60 & 0.61 & 163 \\
\hline Mean & 58 & 2.18 & 0.47 & 148 \\
\hline
\end{tabular}

Table I Kinetics of deoxycholic acid-24-14 $C$ in five female cholecystectomy subjects

\section{COMPOSITION AND SIZE OF THE BILE SALT}

POOL

The relative proportions of cholate, chenodeoxycholate, and deoxycholate in the bile salt pool are shown in figure 5 . The proportion of cholate was significantly smaller in the cholecystectomy group, the mean value $( \pm S D)$ being $33.0 \pm 6.1 \%$ compared with $39.1 \pm 5.5 \%$ in the controls $(P<0.0125)$. The proportion of chenodeoxycholate was also significantly reduced at $21.5 \pm 14.1 \%$ compared with $34.1 \pm 6.8 \%$ in the controls $(P<0.0125)$. Conversely, the proportion of deoxycholate was increased in the cholecystectomy subjects, the mean value ( \pm SD) being $45.5 \pm 14 \cdot 1 \%$ compared with $26.8 \pm$ $9.4 \%$ in the controls $(\mathrm{P}<0.0025)$.

The $G / T$ ratio was similar in the two groups, being on average $2.33 \pm 0.63$ in the controls and $2.79 \pm 1.29$ in the cholecystectomy subjects.

The calculated size of the component bile salt pools is shown in figure 6 . In the cholecystectomy subjects, the cholate pool was reduced by $57 \%$, the mean \pm SD being $0.49 \pm 0.19 \mathrm{~g}$ compared with $1.13 \pm 0.46 \mathrm{~g}$ in the controls $(\mathrm{P}<0.0005)$. The

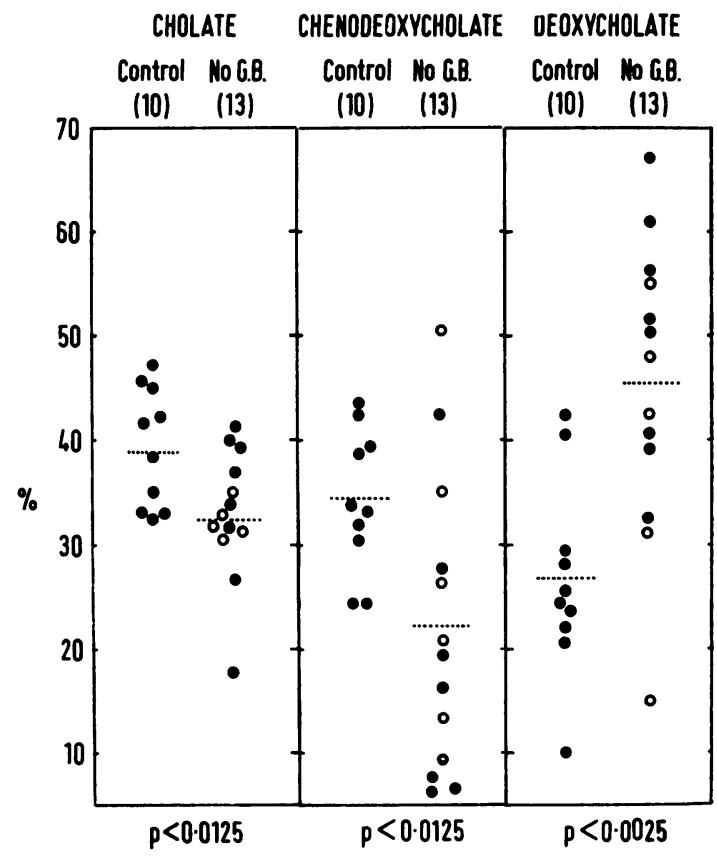

Fig 5 The relative proportions of cholate, chenodeoxycholate, and deoxycholate in the two groups. The open circles represent values calculated from deoxycholic acid-24-14 $C$ studies.

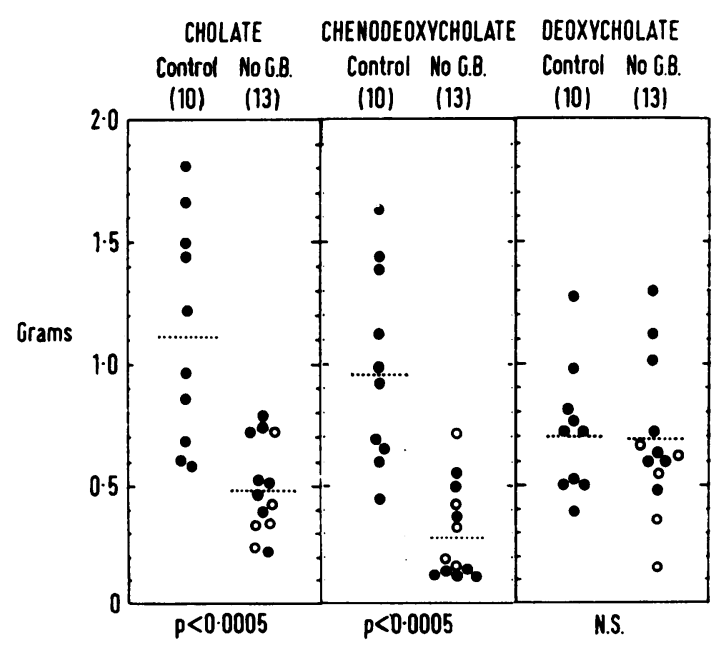

Fig 6 The calculated size of the three component bile salt pools in the two groups. The open circles represent values calculated from deoxycholic acid-24-14C studies. 


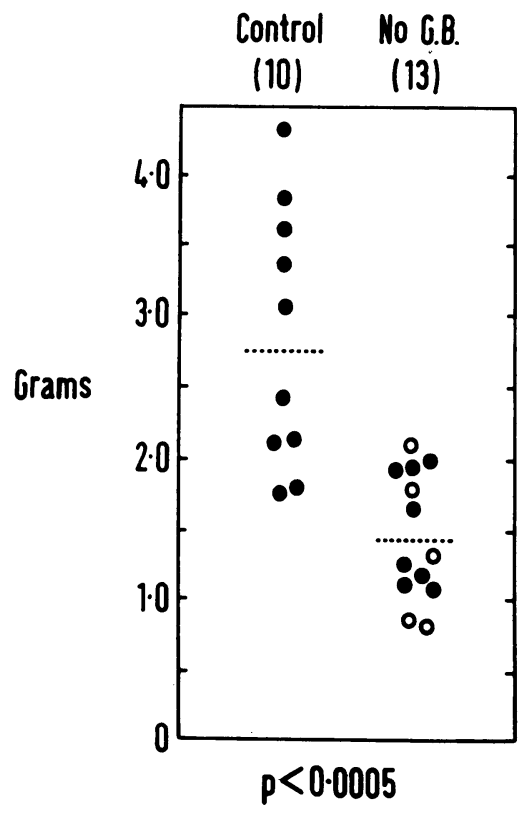

Fig 7 The calculated size of the total bile salt pool in the two groups. The open circles represent values calculated from deoxycholic acid-24-14 C studies.

chenodeoxycholate pool was reduced by $70 \%$, being $0.29 \pm 0.21 \mathrm{~g}$ compared with $0.98 \pm 0.40 \mathrm{~g}$ in the controls $(P<0.0005)$. However, the deoxycholate pool was not significantly different in the two groups (mean $0.68 \pm 0.31 \mathrm{~g}$ in the cholecystectomy group and $0.72 \pm 0.26 \mathrm{~g}$ in the controls). The reduction in the chenodeoxycholate pool was significantly greater than the reduction in the cholate pool $(\mathrm{P}<0.05)$.

The total bile salt pool was significantly reduced in the operated subjects, the mean \pm SD being 1.46 $\pm 0 . \% 5 \mathrm{~g}$ compared with $2.83 \pm 0.91 \mathrm{~g}$ in the controls $(P<0.0005)$ (fig 7).

RECIRCULATION OF LABELLED METABOLITES OF TAUROCHOLATE-24-14 C

Proportion of bile radioactivity in all metabolites of taurocholate (glycocholate, glycodeoxycholate, and taurodeoxycholate)

On each of the four days there was, on average, more radioactivity in these metabolites in the cholecystectomy group, though the difference from the control group was not statistically significant on any one day. The mean values for the four days were, in the control group, $23.1 \%, 47.6 \%, 63.1 \%$, and $68.5 \%$, and in the cholecystectomy group, $29.9 \%, 61 \cdot 1 \%$, $72 \cdot 1 \%$, and $79 \cdot 6 \%$.

Proportion of bile radioactivity in deoxycholate conjugates

On each day, there was a marked and significant increase in deoxycholate radioactivity in the cholecystectomy group (fig 8). The mean values ( \pm SD) for each of the four days were $21.4 \pm 12.8 \%, 47.5$ $\pm 23.2 \%, 58.8 \pm 24.3 \%$, and $66.0 \pm 23.5 \%$ respectively, compared with $8 \cdot 8 \pm 3 \cdot 3 \%, 22 \cdot 4 \pm 12 \cdot 5 \%$, $30.2 \pm 17.8 \%$, and $40.2 \pm 16.0 \%$ respectively in the control group ( $P<0.01$ for each day).

PRE- AND POSTOPERATIVE STUDIES

Four subjects (aged 52-59 years) were studied befor ?

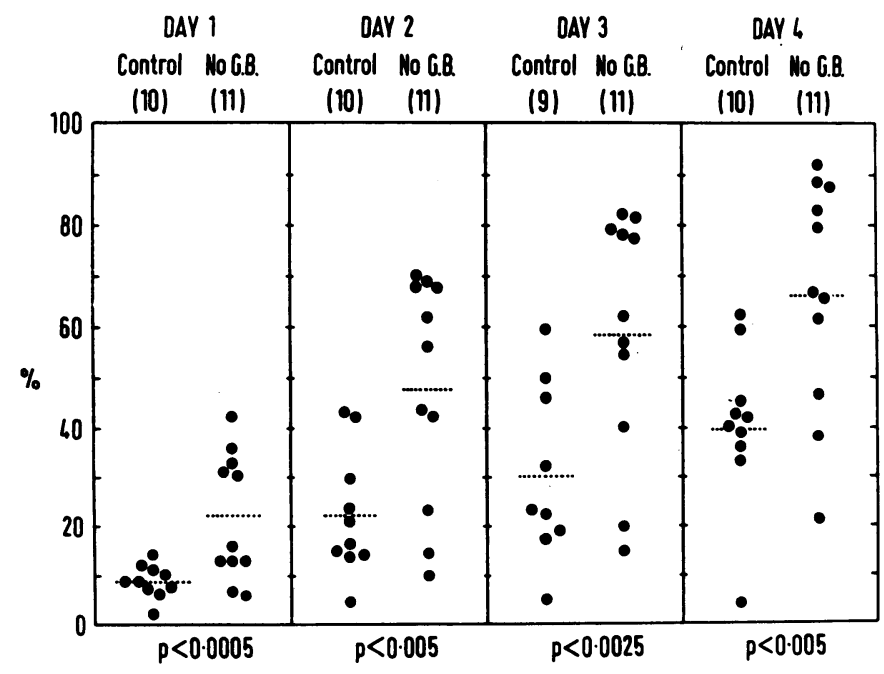

Fig 8 The percentage of bilr radioactivity present in deoxycholate conjugates on each of the four days following administration of sodium taurocholate-24-14 $C$. 


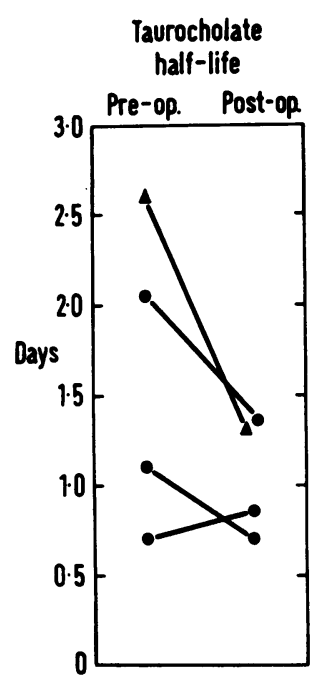

N.S.

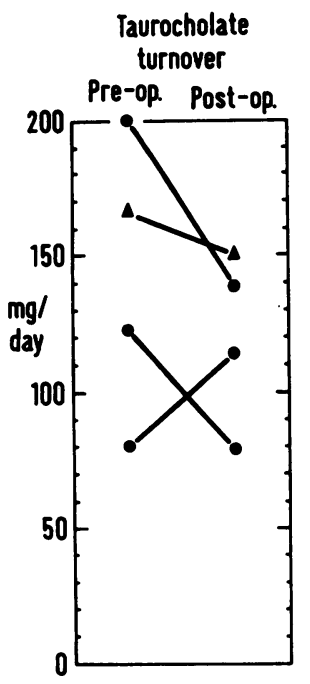

N.S.
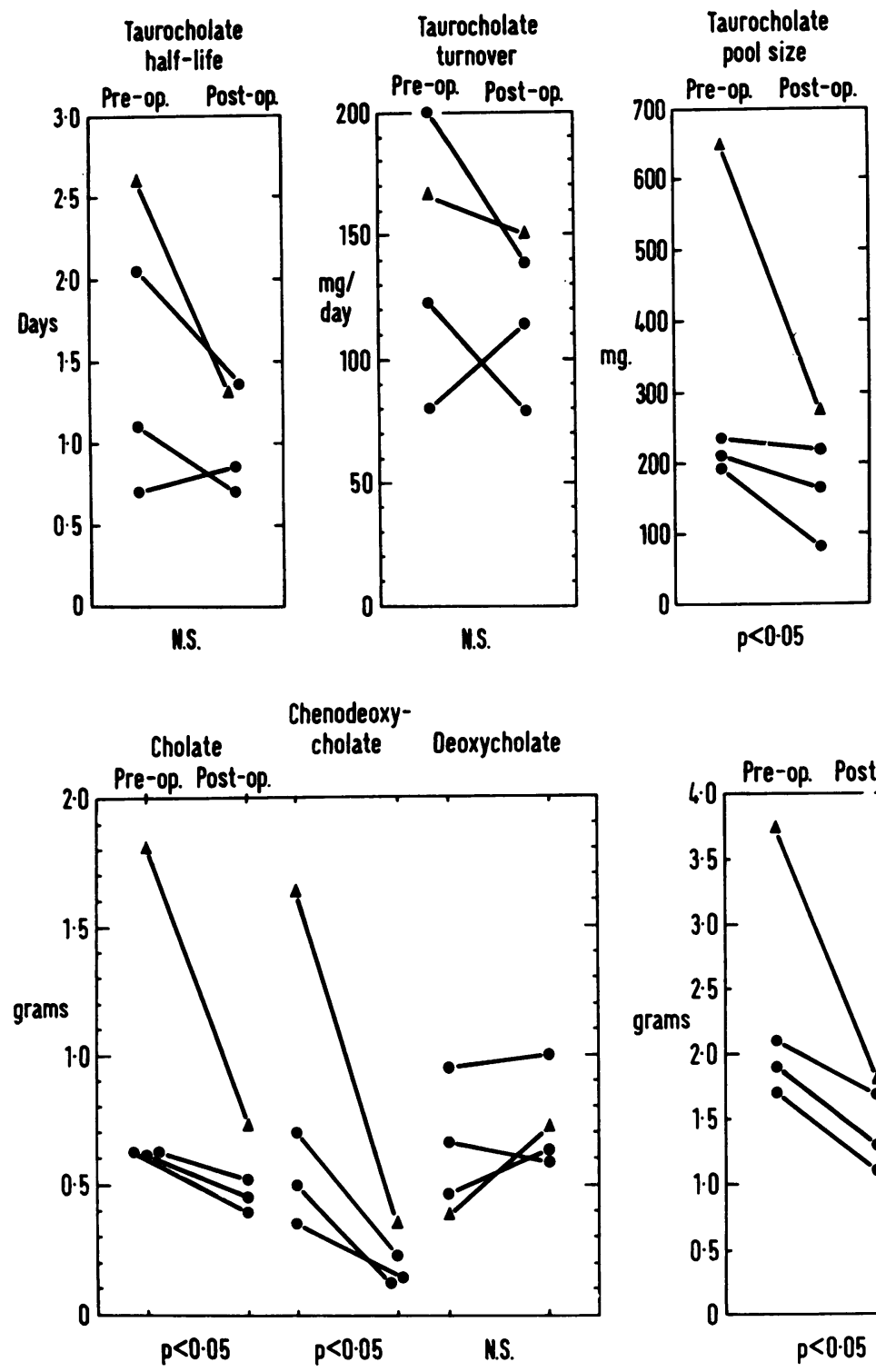

Fig 9 Kinetic data in four subjects studied before and after cholecystectomy. The triangle represents a subject without gallstones and the circles indicate patients with gallstones.
Fig 10 The size of the component and (on the right) total bile salt pools in four subjects studied before and after cholecystectomy. Significance of symbols as in figure 9. and six to nine months after cholecystectomy. In one subject the only abnormality found at operation was a small benign polyp. The other three had cholesterol gallstones. In all eight studies, the bile salt administered was sodium taurocholate- $24-{ }^{14} \mathrm{C}$.

Figures 9 and 10 show the kinetic data pre- and postoperatively. Surgery was followed by significant decreases in the cholate, chenodeoxycholate, and total bile salt pools, the reductions being $45 \%, 74 \%$, and $39 \%$ respectively. The deoxycholate pool increased in three out of the four subjects but overall the change was not significant. Similarly, the taurocholate half-life fell in three out of the four subjects but again the overall change was not statistically significant. The mean taurocholate half-life was 1.59 days before and 1.03 days after operation. The taurocholate synthesis was not significantly affected, the mean pre- and postoperative values being 141 and $120 \mathrm{mg}$ per day.

Figure 11 shows the metabolism data pre- and postoperatively. Cholecystectomy was followed by significantly increased radioactivity in deoxycholate 


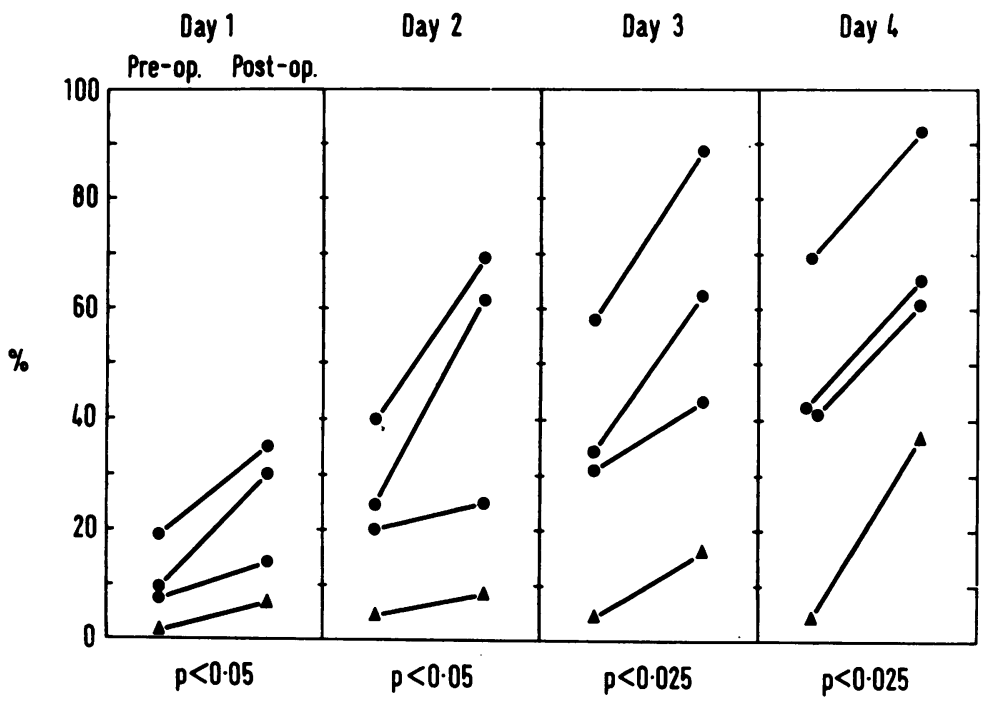

Fig 11 The percentage of bile radioactivity present in deoxycholate conjugates on each of the four days following administration of sodium taurocholate-24-14C. Data in four subjects studied before and after cholecystectomy. Significance of symbols as in figure 9.

conjugates on each of the four days in each of the four subjects.

No significant change occurred in the $\mathrm{G} / \mathrm{T}$ ratio.

\section{Discussion}

We have shown cholecystectomy subjects to have significantly reduced pools of both primary bile salts, cholate and chenodeoxycholate, while the deoxycholate pool remains normal in size. As a result of these changes, the total bile salt pool is reduced to almost half its normal size and deoxycholate becomes the predominant bile salt. The half-life of taurocholate is reduced but, because its pool size is diminished, the daily synthesis of taurocholate remains normal. There is accelerated transfer of ${ }^{14} \mathrm{C}$ from taurocholate-24-14 $\mathrm{C}$ to its metabolites in bile, especially the deoxycholates, which implies increased bacterial alteration of the bile salt pool.

When the gallbladder is removed, the basic physiological change is the loss of a storage place for bile salts between meals and particularly overnight. At such times, the normal subject's bile salt pool is stationary within the gallbladder, which may be regarded as a diverticulum of the enterohepatic circulation (Latin: digression, inn, or lodging). A model for the cholecystectomy situation is provided by animals which lack a gallbladder, such as the rat. In the rat, $70 \%$ of the bile salt pool is present in the small intestine and no less than $25 \%$ in the colon (Bergström, Danielsson, and Samuelsson, 1960). Furthermore, the number of times the pool circulates each day is 12 (Olivecrona and Sjövall, 1959; Shefer, Hauser, Bekersky, and Mosbach, 1969) compared with an estimated six in normal man (Borgström, Lundh, and Hofmann, 1963). These extra circulations presumably occur during fasting. It seems reasonable to assume that in the cholecystectomy subject, the bile salt pool circulates more frequently and spends a greater part of the 24 hours in contact with intestinal bacteria.

According to current concepts, liver synthesis of bile salt is homeostatically controlled by the amount and possibly type of absorbed bile salt passing to the liver in the portal blood, that is, by a negative feedback mechanism (Mosbach, 1972; Low-Beer, Pomare, and Morris, 1972). In the cholecystectomy subject, the operation of this feedback mechanism is altered in two ways. First, the mechanism is active during fasting as well as feeding. Second, the bile salt perfusing the liver includes an increased proportion of deoxycholate. Our finding of reduced primary bile salt pools suggests that, in this situation, liver synthesis is suppressed until the total bile salt pool has shrunk to such an extent that the overall passage of bile salt through the liver returns to the normal level. At this point homeostasis is restored, more frequent circulation of a diminished pool providing the same overall return and hence the same level of feedback control as a normal size pool circulating the normal number of times. If overall return of bile salt is normal, then clearly the overall secretion of bile salt into the intestine is also normal. This would explain why, in spite of a small bile salt pool, fat is digested and absorbed normally (Krondl et al, 1964; Simmons and Bouchier, 1972).

Our studies provide direct evidence of increased bacterial metabolism and especially dehydroxy- 
lation of taurocholate in cholecystectomy subjects. Since dehydroxylation is essentially a function of the colonic flora (Morris, Low-Beer, and Heaton, 1973), our findings suggest that the bile salt pool spends a greater part of the 24 hours in contact with colonic bacteria. Increased dehydroxylation explains why the pool of deoxycholate is normal in size although that of its precursor cholate is diminished. The absolute rate of deoxycholate production may well be normal. Indeed our mean value for deoxycholate production in cholecystectomy patients, $148 \mathrm{mg} /$ day, corresponds fairly well to the report of Hepner, Hofmann, and Thomas (1972) that normal subjects produce glycodeoxycholate at a rate of $130 \mathrm{mg} / \mathrm{day}$. Another possible explanation for relative abundance of deoxycholate is abnormally efficient absorption and so conservation of this bile salt. However, it is improbable that there would be selective conservation of one dihydroxy bile salt and not of another. The other, chenodeoxycholate, is certainly not conserved in cholecystectomy subjects, since its pool is diminished even more than that of cholate. This disproportionate reduction in chenodeoxycholate may actually be caused by the abundance of deoxycholate. In the cholecystectomy patient, circulating a normal sized pool of deoxycholate more often than normal, the daily passage of deoxycholate through the liver is greater than normal. Recently, evidence has been presented for a selective feedback inhibition of deoxycholate on the liver synthesis of chenodeoxycholate, but not of cholate (Low-Beer et al, 1972). Hence the synthesis of chenodeoxycholate is likely to be more suppressed than that of cholate.

In interpreting the shortened taurocholate half-life of cholecystectomy subjects, it must be recalled that taurocholate labelled at the carboxyl position loses radioactivity not only by being excreted but also by being deconjugated. The resultant radioactive cholate may well be reabsorbed and reconjugated, and that part which is reconjugated with taurine will replenish taurocholate radioactivity. However, most will be reconjugated with glycine and the contained radioactivity will remain lost to the taurocholate pool (except for a small fraction which may return after a further deconjugation and reconjugation). If deconjugation is followed by dehydroxylation, then radioactivity is permanently lost to the taurocholate pool. With these points in mind, there are several possible explanations for the shortened taurocholate half-life.

1 The proportion of the taurocholate pool excresed each 24 hours is greater than normal. This in turn could be due to: (a) inefficient absorption of bile salt by the intestine; however, there seems no reason to invoke an intestinal defect in cholecystec- tomy subjects; (b) loss of a fixed mass of bile salt from the enterohepatic circulation with each meal, when the pool is reduced, this fixed mass will constitute an increased proportion of the pool; at present, there is no evidence for or against such a mechanism; (c) more circulations and hence more chances of excretion in any 24 hours; this is a plausible mechanism but it lacks evidence. Excretion of taurocholate inevitably involves its bacterial alteration.

2 The proportion of the taurocholate pool deconjugated, and particularly the proportion dehydroxylated, in each 24 hours is greater than normal. In support of this mechanism, when in the cholecystectomy subjects taurocholate half-life is compared with the percentage of bile radioactivity in total metabolites or in deoxycholate conjugates, there are significant negative correlations for each of the four days of the study (table II). As already discussed,

\begin{tabular}{lllll}
\hline & Day 1 & Day 2 & Day 3 & Day 4 \\
\hline All metabolites & $\mathrm{r}=0.839$ & $\mathrm{r}=0.803$ & $\mathrm{r}=0.785$ & $\mathrm{r}=0.747$ \\
& $\mathrm{P}<0.01$ & $\mathrm{P}<0.01$ & $\mathrm{P}<0.01$ & $\mathrm{P}<0.01$ \\
Deoxycholate & $\mathrm{r}=0.790$ & $\mathrm{r}=0.876$ & $\mathrm{r}=0.817$ & $\mathrm{r}=0.788$ \\
conjugates & $\mathrm{P}<0.01$ & $\mathrm{P}<0.001$ & $\mathrm{P}<0.01$ & $\mathrm{P}<0.01$ \\
\hline
\end{tabular}

Table II Negative correlations between taurocholate half-life and percentage of bile radioactivity in all metabolites of taurocholate and deoxycholate conjugates ${ }^{1}$

${ }^{1}$ Data from cholecystectomy subjects for each day after administration of taurocholate-24-14 C.

increased bacterial transformation can be explained simply on the basis that the bile salt pool spends more of its time in the intestine, especially in the colon. Theoretically, it could also be due to cholecystectomy subjects having a more abundant small intestinal flora. However, we know of no evidence for such bacterial overgrowth. Indeed, since bile salts are bacteriostatic agents (Stacey and Webb, 1947), a small intestine which is continuously perfused with bile salts may tend to harbour fewer bacteria than normal.

We suggest, therefore, that the shortened half-life of taurocholate is explained by the increased risks of bacterial metabolism and possibly of excretion which result from more frequent passage of the bile salt pool down the intestine. It would seem reasonable to assume that glycocholate is treated in the same way as taurocholate, in which case the total cholate pool will have an increased turnover rate, as noted by Kottke (1969).

The results of the pre- and postoperative studies confirm the findings made by comparing cholecystectomy patients with normal controls. Thus, operation was followed by consistent and significant reduction in the sizes of the cholate and chenodeoxycholate pools, with chenodeoxycholate show- 
ing the greater decrease ( $74 \%$ versus $45 \%)$. Likewise, the deoxycholate pool showed no significant change but the total bile salt pool was substantially reduced. Furthermore, operation was followed by a significant increase in the dehydroxylation of taurocholate, and in three of the four subjects by a decrease in the half-life of taurocholate (the exception being a patient with an unusually short half-life preoperatively).

Since all but two of the cholecystectomy group were operated on for gallstones and since unoperated gallstone patients have a reduced bile salt pool (Vlahcevic, Bell, Buhac, Farrar, and Swell, 1970; Pomare and Heaton, 1973), it may be suggested that the small pool of the cholecystectomy patient is due merely to a continuation of her stone-forming propensity. However, this idea can be discounted because (1) all four subjects studied pre- and postoperatively showed a substantial fall in the size of the bile salt pool; (2) in a companion study, unoperated gallstone patients have been found to have bile salt pools which are significantly larger than those of patients who had undergone cholecystectomy for stones (Pomare and Heaton, 1973); (3) it has been shown that cholecystectomy is followed by a change in bile composition, such that the bile is no longer lithogenic (Simmons et al, 1972; Shaffer et al, 1972). A subject in whom such a change has occurred can hardly be regarded as still having the stoneforming propensity.

The present investigation complements a similar one from this laboratory of patients with coeliac disease (Low-Beer, Heaton, Heaton, and Read, 1971; Low-Beer et al, 1973). In that study, exaggeration of the storage function of the gallbladder was noted and this was associated with changes in bile salt metabolism exactly opposite to those found after cholecystectomy, namely, slow turnover and diminished bacterial degradation of an enlarged bile salt pool. Taken together, these investigations throw new light on the physiology of the gallbladder. In particular, they indicate that the reservoir function of the gallbladder is an important determinant of the size, kinetics, metabolism, and composition of the bile salt pool. We suggest, therefore, that no study of bile salt metabolism is complete without some assessment of gallbladder status.

In conclusion, we suggest the following answers to the questions posed in the introduction. (1) Loss of the gallbladder reservoir results in diminution of the two primary bile salt pools. This is attributable to the fact that the bile salt pool circulates during fasting as well as after feeding, so that there is continuous feedback inhibition of hepatic bile salt synthesis. (2) Alteration of bile salts by bacteria is increased, especially dehydroxylation. (3) The turn- over rate of the cholate pool is increased. Both (2) and (3) are attributable to more frequent passage of the bile salt pool down the intestine and consequently more contact between the pool and intestinal bacteria.

We are grateful to Dr Susan T. Heaton for help with the assays, to Miss E. H. L. Duncan and Dr C. A. Pennock for statistical advice, and to Dr T. S. Low-Beer for helpful discussions. The investigation was performed with the aid of a research grant from the United Bristol Hospitals and of a Commonwealth scholarship.

\section{References}

Austad, W. I., Lack, L., and Tyor, M. P. (1967). Importance of bile acids and of an intact distal small instestine for fat absorption. Gastroenterology, 52, 638-646.

Bergström, S., Danielsson, H., and Samuelsson, B. (1960). Formation and metabolism of bile acids. In Lipide Metabolism, edited by K. Bloch, pp. 291-336. Wiley, New York.

Borgström, B., Lundh, G., and Hofmann, A. (1963). The site of absorption of conjugated bile salts in man. Gastroenterology, 45, 229-238.

Bruusgaard, A. (1970). Quantitative determination of the major 3-hydroxy bile acids in biological material after thin-layer chromatographic separation. Clin. chim. Acta, 28, $495-504$.

Dowling, R. H. (1972). The enterohepatic circulation. Gastroenterology, 62, $122-140$.

Heaton, K. W. (1972). Bile Salts in Health and Disease, pp. 58-81. Churchill Livingstone, Edinburgh and London.

Heaton, K. W., Austad, W. I., Lack, L., and Tyor, M. P. (1968). Enterohepatic circulation of $\mathrm{C}^{\mathbf{1 4}}$-labelled bile salts in disorders of the distal small bowel. Gastroenterology, 55, 5-16.

Hepner, G. W., Hofmann, A. F., and Thomas, P. J. (1972). Metabolism of steroid and amino acid moieties of conjugated bile acids in man. II. Glycine-conjugated dihydroxy bile acids. J. clin. Invest., 51, 1898-1905.

Hofmann, A. F. (1962). Thin-layer adsorption chromatography of free and conjugated bile acids on silicic acid. J. Lipid Res., 3, 127-128.

Hofmann, A. F. (1968). Functions of bile in the alimentary canal. In Handbook of Physiology, Section 6: Alimentary Canal, Vol. V, Bile, Digestion and Ruminal Physiology, edited by C. F. Code, pp. 2507-2533. American Physiological Society, Washington, D.C.

Kottke, B. A. (1969). Differences in bile acid excretion: primary hypercholesteremia compared to combined hypercholesteremia and hypertriglyceridemia. Circulation, 40, 13-20.

Krondl, A., Vavrinkova, H., and Michalec, C. (1964). Effect of cholecystectomy on the role of the gallbladder in fat absorption. Gut, 5, 607-610.

Low-Beer, T. S., Heaton, K. W., Heaton, S. T., and Read, A. E. (1971). Gallbladder inertia and sluggish enterohepatic circulation of bile-salts in coeliac disease. Lancet, 1, 991-994.

Low-Beer, T. S., Heaton, K. W., Pomare, E. W., and Read, A. E. (1973). The effect of coeliac disease upon bile salts. Gut, 14, 204-208.

Low-Beer, T. S., Pomare, E. W., and Morris, J. (1972). Control of bile salt synthesis. Nature [new Biol.], 238, 215-216.

Morris, J., Low-Beer, T. S., and Heaton, K. W. (1973). Bile salt metabolism and the colon. Scand. J. Gastroent., 8, 425-431.

Mosbach, E. M. (1972). Hepatic synthesis of bile acids. Arch. intern. Med., 130, 478-487.

Olivecrona, T., and Sjövall, J. (1959). Bile acids in rat portal blood. Acta physiol. scand., 46, 284-290.

Pomare, E. W., and Heaton, K. W. (1973). Bile salt metabolism in patients with gallstones. Gut, 14, in press.

Shaffer, E. A., Braasch, J. W., and Small, D. M. (1972). Bile composition at and after surgery in normal persons and patients with gallstones. New Engl. J. Med., 287, 1317-1322.

Shefer, S., Hauser, S., Bekersky, I., and Mosbach, E. M. (1969). Feedback regulation of bile acid biosynthesis in the rat. J. Lipid Res., 10, 646-655. 
Simmons, F., and Bouchier, I. A. D. (1972). Intraluminal bile salt concentrations and fat digestion after cholecystectomy. S. Afr. med. J., 46, 2089-2092.

Simmons, F., Ross, A. P. J., and Bouchier, I. A. D. (1972). Alterations in hepatic bile composition after cholecystectomy. Gastroenterology, 63, 466-471.

Sjövall, J. (1959). On the concentration of bile acids in the human intestine during absorption. Acta physiol. scand., 46, 339-345.

Stacey, M., and Webb, M. (1947). Studies on the antibacterial properties of the bile acids and some compounds derived from cholanic acid. Proc. roy. Soc. B., 134, 523-537.

Turnberg, L. A., and Grahame, E. (1970). Bile salt secretion in cirrhosis of the liver. Gut, 11, 126-133.
Vlahcevic, Z. R., Bell, C. C., Jr., Buhac, I., Farrar, J. T., and Swell, L. (1970). Diminished bile acid pool in patients with gallstones. Gastroenterology, 59, 165-173.

Wollenweber, J., Kottke, B. A., and Owen, C. A. (1966). Effect of nicotinic acid on pool size and turnover of taurocholic acid in normal and hypothyroid dogs. Proc. Soc. exp. Biol. (N.Y.), 122, 1070-1075.

Wollenweber, J., Kottke, B. A., and Owen, C. A. (1967). Pool size and turnover of bile acids in six hypercholesterolaemic patients with and without administration of nicotinic acid. J. Lab. clin. Med., 69, 584-593. 